\title{
Enhancing the Quality of Learning and Understanding of First Year Mathematics for Computer Science Related Majors
}

\author{
Francis Suraweera \\ University of Tasmania, Tasmania, Australia
}

Francis.Suraweera@utas.edu.au

\begin{abstract}
Most courses on Discrete Mathematics are designed to emphasize problem solving, in general. When the goal is to cover the content, the learning and understanding takes a second place. Over time, the students' understanding will have large gaps of knowledge that leads to non-enjoyment of the course and a great deal of anxiety. Given the choice, most first year students would not do the Discrete Mathematics course. It is not an easy course to teach because of the opposing expectations of the instructor and students. However, as instructors, we all share a common goal: we would like our students to acquire the skills to perform complex mental operations so that they will be successful in the classroom as well as their future careers. In this paper, we present a way to enhance the learning and understanding of Discrete Mathematics whether it is offered in a distance learning mode or a traditional classroom situation.
\end{abstract}

Keywords: Computer Science education, mathematics instruction, problem solving, Bloom's taxonomy, and quality of learning.

\section{Introduction}

For many semesters, I have been teaching an introductory Mathematics course, namely: Discrete Mathematics \& Logic to first year Computing and Information Technology (IT) students. Many universities tend to do this by way of service teaching. By this I mean that, they get some one from the Department of Mathematics to do this teaching for you. This practice has led to less than satisfactory results. Even if you are fortunate enough to enlist an applied mathematician, he or she may not know the current computer and IT applications well enough to motivate the students. Generally they tell the students what they are studying is important to their future and cover the content. One has to know the subject matter quite well to show a variety of applications and convince the student skeptics.

If you are you one of those college instructors who teach introductory mathematics to first year Computer Science and Information Technology students then you will share my concern about the Mathematical abilities of incoming students. Not only their mathematical skills are below average but they also come with certain attitudes and behaviors that make further progress extremely difficult. Except for a few good students the majority is of the opinion that mathema tics is an esoteric course and it has no

Material published as part of these proceedings, either on-line or in print, is copyrighted by Informing Science. Permission to make digital or paper copy of part or all of these works for personal or classroom use is granted without fee provided that the copies are not made or distributed for prof it or commercial advantage AND that copies 1) bear this notice in full and 2) give the full citation on the first page. It is permissible to abstract these works so long as credit is given. To copy in all other cases or to republish or to post on a server or to redistribute to lists requires specific permission from the publisher at Publisher@Informingscience.org place in a Computer Science or an IT curriculum. The responses to the question, "do you like mathematics?" is given next. Except for a few, the majority had sentiments ranging from minimal liking to hating the course. A few honest ones said that they are doing it because it is a required course for the degree. Some even said that they 


\section{Enhancing Quality of Learning and Understanding}

want to be programmers and they cannot be bothered with irrelevant stuff.

In general, our first year classes are a diverse group of students consisting of school leavers, mature age, and foreign students. To exacerbate the matters further, the first year classes tend to be quite large. While teaching such classes, I often wonder from where did the students acquire these negative ideas regarding Mathematics. Presumably our society (Mathematics is only for the geniuses or nerds) and some high school Mathematics teachers (who shaped them this way) have contributed a great deal to this sorry state. Since this seems to be the norm in every department, how would you teach Mathematics to such a group of students?

The purpose of this paper is to show, based on personal experience, how an instructor should approach the various topics in Discrete Mathematics so as to facilitate a greater understanding. Our purpose here is not to make them mathematicians. For these students, mathematics is and will always be a vehicle for understanding of the salient computer and IT concepts. We do not intend to show how to teachevery topic in a Mathematics course. Clearly, such an exercise is beyond the scope of this paper. Instead, we take you through a few examples to exemplify our approach, which we believe has been quite successful in teaching such classes.

\section{The Approach}

Suppose that on a particular day (or a module) you want to teach series (arithmetic, geometric, etc.) to the class.

\section{Problem 1.}

Find the sum of $1+2+3+\ldots+n$.

Before we proceed any further, perhaps, we should ask the class (or the audience) why it is important to know the sum of the above series. Have they seen this problem or something similar to this before? Will we ever use it in real life or in our future careers? Let the audience/class reflect on these questions for a minute or so.

Instructors of Computer Science know that this series comes up frequently when analyzing the complexity of algorithms. However, the students have not seen this yet. So what do we do? There are two possibilities, namely, (a) go straight to theory and work out the solution, and (b) the practical approach, where you take the time to relate to their experience and try to make it an enjoyable experience. Clearly it takes a little while, but your students will be ever so grateful to you and they will remember you long after they ha ve left your class.

Let us try the practical approach. Show how what they are studying is important to their future, and to their long-term goals. It is also important to engage students actively in class discussions. Ask them if they can remember an activity such as riding a bicycle for the first time as a small child. Many will recall that it did not go smoothly, and that it took many unsuccessful attempts before they got the confidence to ride the bicycle. Remind the class that initial unsuccessful attempts never prevented us in the past in what we wanted to do.

At this time you digress, and tell the class about Alice, a neighborhood teenager, who found part-time summer employment after graduating from high school. Her job was to read to the elderly mother of an eccentric millionaire. The terms of payment was agreed as follows. On day one, Alice will get a (small) silver coin; on day two, Alice will get two silver coins; and on day three, Alice will get three silver coins and so on. If Alice stopped work after $\mathrm{n}$ days, how many silver coins will she collect?

There are three ways to find the answer. (a) After the last day, Alice can count all the coins one by one. Everyone knows how to count. (b) After every day Alice can keep a running total. Again we know how 
to add two numbers together. This process is reminiscent of checkbook balancing. Every time you write a check, you keep a running total of how much you have spent. Recall how embarrassing it is to have a check bounced because there is not enough money in your bank account, and (c) Compute the answer even before you agreed to work; may be you want to find whether it is worth your while to do this parttime job. What is interesting is that most students can relate to this situation, and they can come up with at least some partial answers by themselves. Additionally, it builds up their confidence. Resourceful instructors can engage the class to do some critical thinking (Dromey, 1982; Polya, 1945). When you get the students to this stage, you are on a winning track.

Suppose that you want to tell the class where this result will be useful; you may do this by taking an instance of the selection sort (some call it the maximum sort) problem (Cormen et. al., 1990). Try working out the total number of comparisons for the entire sort. Assume that there are $n$ items to sort. To find the largest, one has to do (n - 1) comparisons, to find the next largest we need (n - 2) comparisons, and so on down to 3,2 , and 1 . Then we get the following summation.

$$
(n-1)+(n-2)+(n-3)+\ldots+3+2+1
$$

Now write the same numbers in the reverse order.

$$
1+2+3+\ldots+(n-3)+(n-2)+(n-1)
$$

This is the same summation as our original problem except that the last term, $n$, is not there. Now to find the solution, proceed as follows.

Let $\mathrm{S}=1+2+3+\ldots+(\mathrm{n}-2)+(\mathrm{n}-1)+\mathrm{n}$

Also, $\mathrm{S}=\mathrm{n}+(\mathrm{n}-1)+(\mathrm{n}-2)+\ldots+3+2+1$

The last line is the same set of numbers written in reverse order. Adding the two lines, column by column, we get:

$$
2 \mathrm{~S}=(\mathrm{n}+1)+(\mathrm{n}+1)+(\mathrm{n}+1)+\ldots . .+(\mathrm{n}+1), \text { and there are nsuch terms. }
$$

Thus, $2 \mathrm{~S}=\mathrm{n}(\mathrm{n}+1)$

$$
\mathrm{S}=\mathrm{n}(\mathrm{n}+1) / 2
$$

This result is due to Gauss, the famous German mathematician. According to legend Gauss was only 8 years old when he did this. This formula is quite useful, and when you use it a number of times it gets committed to the memory. Even if the student forgets it, he or she can derive the formula using the above method quickly.

\section{Problem 2.}

Find the sum of $1+2^{1}+2^{2}+2^{3}+\ldots+2^{\mathrm{n}-1} \quad$ (Geometric series)

Think of an $8 \times 8$ square grid, for example a chessboard. Do the following row by row. Place one penny in the first square; place double the previous number of pennies (= 2 pennies) in the second square; double the previous number ( $=4$ pennies) and place it in the third square and so on. On the last square you would be placing $2^{63}$ pennies. In practice, after sometime, one may not be able to place so many pennies on the squares; however, you can write these numbers on pieces of paper and keep them on the corresponding squares. What is the total number of pennies? From this answer one may be able to deduce the answer to our Problem 2. 


\section{Enhancing Quality of Learning and Understanding}

There are other stories that one can relate to the same problem. According to legend an Indian king had a daughter who was suffering from a rare form of a disease. The king summoned all renowned physicians of the country and none was able to cure her. One day a wise man came to the palace and he was able to cure her completely. The king was very pleased and promised that he would give any thing the man asked for. The wise man did not want any thing but the king insisted. Then the man said, if the king pleases, he would like to have grains of rice. He narrated the above problem. (Replace a penny by a measure of rice.) Without thinking, the king ordered that the man's wish be granted. They were unable to fulfill the man's wish. Why?

Let $\quad S_{n}=1+2^{1}+2^{2}+2^{3}+\ldots+2^{n-1}$

Multiply equation (2) by 2 , and displace every term one place to the right and write it under the above equation.

$$
2 S_{n}=2^{1}+2^{2}+2^{3}+\ldots+2^{n-1}+2^{n}
$$

Subtracting equation 2 from 3 , (notice how certain terms cancel pair-wise) we get

$$
S_{n}=2^{n}-1
$$

When $\mathrm{n}=64$, this sum is a humongously large number.

This geometric series is useful in finding the properties of a complete binary tree, analyzing the binary search etc. (Baase, 1987; Bloom et. al., 1959; Brassard \& Bratley 1996; Grimaldi 1994).

The rapidly increasing nature of powers of two can be demonstrated by the following example. Thirty years ago, my high school mathematics teacher (RW) said, "How would you like to go to the moon using an inexpensive method?" This statement aroused everyone's curiosity and we were waiting eagerly to know the method. Then he took one double page out of the daily newspaper and gave it to me and asked me to tear it down the middle. He put the two pieces on top of each other. Then he asked me to tear the paper in the middle and put all the four pieces on top of each other. Next he asked me to tear the paper again in the middle and put all the eight pieces on top of each other and so on. It was easy to see the pattern. At each stage, the number of sheets of paper doubled. If we were to do this 64 times, he wanted to know how many sheets of paper would there be on top of each other. The class said it was $2^{64}$. Then he said all you have to do is to stand on top of the stack of paper. The height of the stack is more than the distance to the moon! (readers should work this out taking the width of paper to be one tenth of a millimeter. See what happens if the width of the paper were one hundredth of a millimeter.)

\section{Problem 3.}

Matrices is yet another topic that brings a great deal of anxiety to first year college students. Although it is a versatile data structure (Baase 1987; Brassard \& Bratley 1996; Cormen et. al., 1990; Horowitz \& Shahni 1978) and used in solving systems of equations (Epp, 1995; Grimaldi 1994), does any of these convince our student skeptics? Have we tried to understand what really bothers our students. Given two matrices $\mathrm{A}(\mathrm{mxn})$ and $\mathrm{B}(\mathrm{sxt})$, let us take a good look at the definition of matrix multiplication. Assume that the number of columns, $n$, of the first matrix is equal to the number of rows, $s$, of the second matrix. (this is the condition required to multiply the two matrices together.) Let $\mathrm{C}=\mathrm{AxB}$; then

$$
\mathrm{C}_{\mathrm{i}, \mathrm{j}}=\sum \mathrm{a}_{\mathrm{i}, \mathrm{k}} \times \mathrm{b}_{\mathrm{k}, \mathrm{j}} \quad \mathrm{k}=1,2,3, \ldots, \mathrm{n}
$$

The above definition has one summation, three double suffixes, three indexes $\mathrm{i}, \mathrm{j}$, and $\mathrm{k}$ and so on. There are too many symbols in one place. One double suffix is bad enough for our students, and when you have several, it is worse. Granted that they would have seen matrix equality and matrix addition, still it is too abstract for them. 
Here is a gentle way to start matrices. Suppose there are four college students whose names are Alice, Bob, Chris, and Fran. We may even ask four students from the class to role-play. College students consume a lot of beverages (say, coffee and sodas) and candy bars during a day. Let us find out how many of each kind is consumed by our four students in a day and record this information in a table. Using Table 1 , it is easy to introduce elementary ideas of matrices. If we remove the window dressing - that is, the left- most column containing all the names and the top row containing the names of the consumables - what is left is a $4 \times 3$ matrix. Now, we may introduce the idea of rows and columns. Questions like "how many candy bars are eaten by Alice in a day" are easy to read off the matrix. In the absence of names like Chris, Fran and Coffee, it becomes logical to use the idea of rows and columns. We may ask for the same information as what is the value of the element at the position $(1,3)$ ? This pairing of numbers is not entirely new to the students. They use the street maps (the grid system) and they already know phrases like "the intersection of Vine Street and the $12^{\text {th }}$ ". They have seen how to draw graphs on the Euclidean plane using the $(x, y)$ coordinates. The important thing here is to relate to their past experience. Once they see the connection, the double suffix would not pause much of a difficulty. Gradually introduce the idea of shape (= the order) of a matrix, the diagonal etc.

\begin{tabular}{l|lll} 
& Coffees & Sodas & $\begin{array}{l}\text { Candy } \\
\text { bars }\end{array}$ \\
\hline Alice & 1 & 4 & 2 \\
Bob & 2 & 6 & 1 \\
Chris & 4 & 2 & 3 \\
Fran & 3 & 3 & 0
\end{tabular}

Table 1. Beverage consumption per day of four college students

Assuming that the students' daily intakes do not change we can work out the total consumption for two days. This leads to addition of two matrices or multiplication by a scalar (in this case, 2). We may also point out the condition that is required for addition of two matrices, is that the two matrices must have the same shape. The rule is to add corresponding elements.

Suppose the price of a coffee, a soda, and a candy bar is $\$ 1.40, \$ 1.10$ and 80 cents respectively. This information is shown in Table 2, below.

\begin{tabular}{l|l} 
& Price \\
\hline Coffee & 140 \\
Soda & 110 \\
Candy bar & 80
\end{tabular}

\section{Table 2. Prices of consumables in cents}

Question. How much does Alice spend per day on beverages and candy bars? The instructor can show how this leads to matrix multiplication and also to the expression

$(A B)_{11}=a_{11} b_{11}+a_{12} b_{21}+a_{13} b_{31}$ which is equal to the $(1,1)$ element of the product matrix.

$$
=1 \times 140+4 \times 110+2 \times 80 \text { (cents) }=\$ 7.40
$$




\section{Enhancing Quality of Learning and Understanding}

Similarly, the other elementary matrix operations may be introduced in a less stressful fashion. From personal experience we have found that this is a better way, and after the class students would come up to you and say that they understood matrices for the first time in their lives. The rest of the topics in the course can be introduced in a similar fashion. Experienced instructors know how to come up with good scenarios that will catch the attention of their students.

All the strategies that we use in a traditional classroom could easily be translated to a distance education mode. Since distance education means different things to many people, first, let us give a working definition of this term. It is the learning and teaching that occurs when the student and the teacher (= facilitator) are not necessarily in the same place and/or interacting at the same time. This has given rise to the popular phrase "whenever and wherever" to our vocabulary. The material for a course is transmitted or delivered in several ways. These are: the radio, postal deliveries, the telephone, the television, closecircuit TV, video conferencing, demonstrations and lectures delivered via satellite etc. Today we also use the World Wide Web quite heavily for dissemin ation of content whether it is the distance education mode or the traditional classrooms. The WWW has a variety of tools for presenting information, including videos and animations. The latter mechanisms have the advantage of eliciting longer attention spans from the students.

\section{Quality of Learning}

The strategies described above would improve vastly the understanding of students taking introductory Mathematics at the first year level. Now, how do we evaluate the effectiveness of this method? It is one thing to say: "based on our observations and the students' ability to solve exercises". One of the ways to evaluate the efficacy of any learning strategy is through Bloom's Taxonomy (Bloom et. al., 1959). Below we list Bloom's taxonomy starting from the lowest level to the highest.

Bloom's Taxonomy for Cognitive Skills

- Knowledge - this level means that, the student acquires knowledge and is able to reme mber facts;

- Comprehension - the student understands the information or skills, underlying relations and context;

- Application - the student is able to apply their knowledge and understanding to new areas;

- Analysis - the student can analyze and find the component parts of the problem;

- Synthesis - the student can create something that is relatively new; and

- Evaluation - the students can give well-supported judgments based on facts in their field.

In general, our strategy will achieve all levels of the above taxonomy. Of course, every problem that we try to solve in the first year will not require all the cognitive levels as proposed by Bloom. It depends very much on the problem at hand. However, we want to ensure that our students will go through the entire continuum. To achieve the higher levels - analysis, synthesis and evaluation - we gave challenging problems and/or projects to the students.

\section{Projects}

Next we present a concept - the mini research problem - for a deeper understanding of the material co vered in the class. This focuses on students' learning and address all aspects of the taxo nomy proposed by Bloom (op. cit). The best way to present this to the class is to give a hand out describing the project or the problem that they have to solve. Alternatively, the same could be posted on the teaching web site for the course. An example is given below. Obviously, every student will not understand all aspects of 
the project after the first reading. It is expected (and also encouraged) that students will come back for more clarification. This could be done through a face-to-face conversation or a through an email or a chat session in the case of a distance education situation. Instructors should be prepared for putting more time for this activity and giving feedback. Alternatively, the instructor may explain the project during class time. Detailed instructions of what's to be submitted are also given to the class at this time.

\section{Description of the Project:}

You and your study partner, Pat, are considering how to design a new algorithm for the min imum-cost spanning tree problem (Baase, 1987; Brassard \& Bratley, 1996; Cormen et. al., 1990; Epp, 1995; Grimaldi, 1994). You have decided not to use any of the known algorithms for the minimum-cost spanning tree (MST) while doing this. Your starting point is a connected, weighted graph $\mathrm{G}=(\mathrm{V}, \mathrm{E})$ with $|\mathrm{V}|=n$ nodes, and $|\mathrm{E}|=m$ edges.

Pat says, "an MST has to be a spanning tree; therefore, I will first get rid of all the cycles in the given graph without disconnecting it". Pat also realizes that the weight of the spanning tree must be a minimum. To achieve this, she says, I will remove the heaviest edge while breaking each cycle. Ties will be broken in an arbitrary fashion. Pat knows that this is a greedy algorithm, and she is very hopeful it might produce a minimum spanning tree.

Now it is your turn and you say, "Gee, this is an idea that might actually work. However, we do not know how good (- complexity wise) the algorithm is. First, we have to come up with a procedure to find a cycle (= circuit) of a given graph. And we have to apply this procedure several times until we get a spanning tree."

At this point Pat says, "A cycle is a set of edges that are back-to-back and has the same starting and finishing node. Therefore, we have to design a general procedure that will accomplish this. When we know all the edges, we can also identity the heaviest edge in the set.

Do some initial research. You may use your popular search engine for this. Then follow up some of the references.

Your task is to design an algorithm along the lines described above. Prove the correctness of your algorithm. Show also how to obtain the complexity of your algorithm.

Submit the solution by - give a date here. Only typed copies will be accepted.

What is to be included in the submission?

- Give an introduction to the problem; perhaps, one or two applications - think about where you can apply such a result.

- The algorithm - must be crisp, precise and should be written using the standard template that we studied in the class. You may need to rewrite it a couple of times.

- The proof of correctness; this is the part where you prove that your prescription really works.

- The complexity calculations.

- Finally, include a section on conclusions and reflections. You must give 3 - 5 relevant references from the literature. Also include some conference and journal papers. Use a standard style for citing references in the body and at the end of the paper.

NB. Good writing style is encouraged. Draw diagrams to illustrate your ideas. Define all new terminology. You will lose marks for incorrect grammar and spelling. Your submission should not exceed 4 typed pages. Submissions should take the form of a paper in Information Processing Letters (or substitute your favorite journal, here). 


\section{Enhancing Quality of Learning and Understanding}

It should be noted that the project is designed to develop the higher levels of understanding - namely, analysis, synthesis and evaluation (see, Bloom's Taxonomy given above). Resourceful instructors will be able to find a number of such projects covering the content of the course. I have used the project as an assessment item and have seen that it really changed the way students learn.

\section{Summary and Discussion of the Approach}

The examples presented earlier show what we can do to enhance the students' learning and understanding of Mathematics. On the surface, it appears that we have to tell stories and keep them entertained in the classrooms. In contrast, what is actually happening is that we are assisting our freshmen students in developing strategies to pick up the major concepts (the abstractions, the theory etc.) by relating to the students' experiences. Effective instruction builds upon this experience deliberately because functionally individuals will interp ret and incorporate new ideas through their existing frames of reference (Kolb, 1984). According to Kolb's learning model individuals form abstract concepts and generalizations by reflecting on experience (Polya, 1945). Good instruction should guide students consciously through this process.

Some academic friends of mine who are mathematicians and teaching similar courses in other schools tend to see the beauty of Mathematics. (Indeed, to the specialist, mathematics is beautiful.) For them covering the content takes the center stage. This may be a good strategy for students in a mathematics department. Recall that our students have an aversion to Mathematics. We hope that all our students would "learn to think critically" for themselves, have a deeper understanding of concepts and not ask the question "Will this be on the test?" Additionally, the project idea will also give the students good presentation skills. That is, they will acquire effective communication (in this case, writing) skills.

A good instructional strategy for motivating students is to pose a problem or a question related to the day's topic at the beginning of each class. This creates a sense of mental disequilibrium that promotes thinking. Note that some of the questions and scenarios we posed while presenting the problems on series were designed to have the same effect on the class. Clearly, thinking and learning are inseparable processes. Once you emphasize that thinking (Cormen et. al., 1990; Polya, 1945) is important to solving problems, you should give students ample opportunities to practise applying those skills to a variety of course related problems. These can be found at the end of the relevant chapters in the following textbooks, see for example (Epp, 1995; Grimaldi, 1994). A colleague of mine who teaches Discrete Mathematics has designed an automated tool called the MathAsset for this purpose. It generates nume rous examples on a computer screen so that students can practise on a variety of problems. After using this as a practicing tool, they then take the assessment for that module. The automated assessment feature of the MathAsset saves a lot of time spent on grading and giving feedback because the software does the grading for you. The students enrolled in the course will get a password and then they can access it any time of the day or the night for the purpose of self-practice or assessment.

Instructors who are familiar with Bloom's Taxonomy for cognitive skills can take advantage of the continuum for designing the course efficiently. Once you become familiar with the levels of learning, instructors can use this added knowledge or wisdom to translate the course material in a more meaningful fashion. Resourceful instructors can then ask or set questions within particular levels of the taxonomy to consciously guide the learning process. This greatly facilitates the presentation of information to the students as well as assessment. The entire process becomes so simple and can be applied to teach any course!

\section{References}

Baase, S. (1987). Computer algorithms: Introduction to design and analysis (2 $2^{\text {nd }}$ ed.). Addison-Wesley. 
Bloom, Benjamin S., Mesia, Bertram B., \& Krathwohl, David R. (1950). Taxonomy of educational objectives (two vols: The affective domain \& the cognitive domain). New York: David McKay.

Brassard, G., \& Bratley, P. (1996). Fundamentals of algorithmics. Englewood Cliffs, NJ: Prentice-Hall.

Cormen, T. H. et al. (1990). Introduction to algorithms, Cambridge, MA:The MIT Press.

Dromey, R. G. (1982). How to solve it by computer. Prentice-Hall.

Epp, S. (1995). Discrete mathematics with applications. Pacific Grove, California: Brooks/Cole Publishing.

Grimaldi, R. (1994). Discrete and combinatorial mathematics - An applied introduction ( $3^{r d}$ ed.). Addison-Wesley Publis hing Co mpany.

Horowitz, E., \& Sahni, S. (1978). Fundamentals of Computer Algorithms. Computer Science Press.

Kolb, D. A. (1984). Experiential learning: Experience as the source of learning and development. Englewood Cliffs, NJ: Prentice Hall.

Polya, G. (1945). How to solve it: A new aspect of mathematical model: Princeton University Press.

\section{Biography}

Dr. Francis Suraweera did his undergraduate studies at the University of Ceylon, Peradeniya, Sri Lanka. Later he earned his PhD degree from the University of Dundee, in the United Kingdom. Dr. Suraweera has been teaching in several countries at both the undergraduate and postgraduate levels. Currently, he is an Associate Professor in the School of Computing, University of Tasmania. Good teaching is one of his passions, and he is actively involved in problem-based learning. 